The ERS designates this educational activity for a maximum of 1 CME credit. For information on how to earn CME credits, see www.ers-education.org/ publications/breathe.aspx

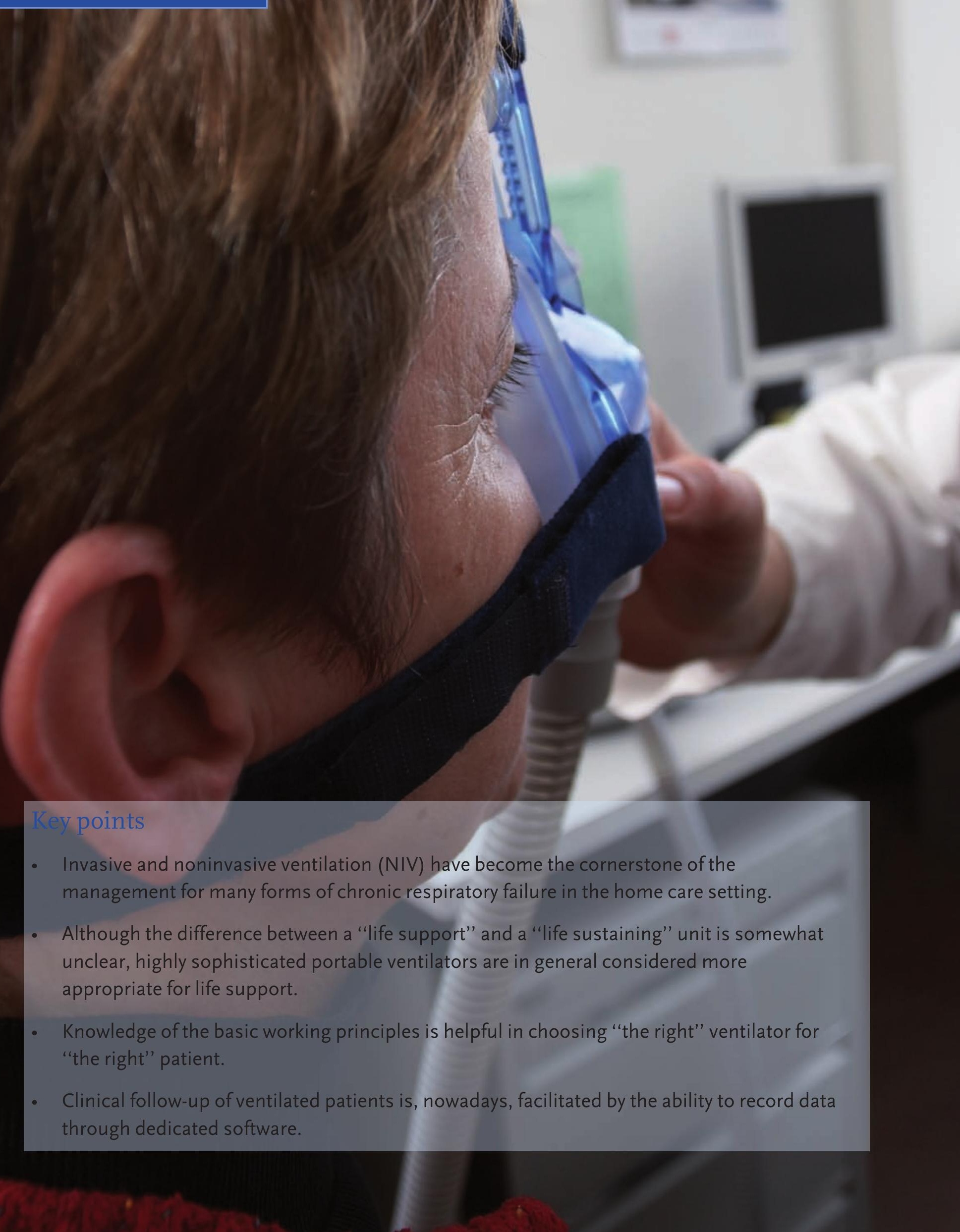



$\Omega$
C. Gregoretti ${ }^{1}$
P. Navalesi ${ }^{2}$
S. Ghannadian ${ }^{3}$
A. Carlucci ${ }^{4}$
P. Pelosi ${ }^{5}$
'Dipartimento di Anestesia e Medicina degli Stati Critici,
'Dipartimento di Anestesia e Medicina degl
Città della Salute e della Scienza, Torino
${ }^{2}$ Dipartimento di Medicina Traslazionale,
Università del Piemonte Orientale "A. Avogadro", Novara
SC Anestesia e Rianimazione, Ospedale Sant'Andrea,
Vercelli, CRRF Mons. L. Novarese, Moncrivello (VC)
${ }^{3}$ Servizio di Anestesia e Rianimazione,
Ospedale S. Croce e Carle, Cuneo
${ }^{4}$ Pneumologia Rabilitativa e Terapia Semintensiva
Respiratoria, IRCCS-Fondazione S. Maugeri, Pavia
${ }^{5}$ Dipartimento Scienze Chirurgiche e Diagnostiche Applicate,
Università degli Studi di Genova, IRCCS AOU San Martino-
IST, Genova, Italy
C. Gregoretti: S. Da delle c.gregoretti@gmail.com Terrazze 56/12, 10133
Torino, Italy

\section{Choosing a ventilator for home mechanical ventilation}

\section{Educational aims}

$\odot$ To discuss the basic principles of ventilator function

$\odot$ To help the reader to recognise the different features of a home care ventilator

$\odot$ To outline the advantages and drawbacks of the different home care ventilators

$\odot$ To provide some recommendations to facilitate the clinical management of patients on home care ventilator

\section{Summary}

Mechanical ventilation, applied either invasively through a tracheotomy tube or noninvasively via a mask, is increasingly used for long-term management of many forms of severe chronic respiratory failure in the home setting. In recent years, the quality of the ventilators for long-term home mechanical ventilation has improved considerably and, concomitantly, the number of machines available has also increased. This broader range of commercially available machines is clearly an advantage; however, it makes the choice of the optimal device for a specific patient more difficult. The aim of the present article is to provide useful information to help and guide the choice of device for long-term mechanical ventilation in the home setting.

Mechanical ventilation, applied either invasively through a tracheotomy tube or noninvasively via a mask, is increasingly used for the long-term management of many forms of severe chronic respiratory failure in the home setting [1-3].

A wide range of home care ventilators ( $\mathrm{HCV}$ ) are now available for long-term mechanical ventilation [4-7]. HCVs are heterogeneous with respect to technical performance and reliability $[6,8]$, and their user-friendliness for the operator $[9,10]$. However, this extended range of commercially available machines makes the choice of the best device for different categories of patients more difficult [8]. Further, manufacturers often propose new ventilatory modes, but, as in the acute critical care setting [11], scientific evidence of their
Statement of Interest Cesare Gregoretti has received consulting fees or honorarium from Covidien, Sapio Life, Smiths Ind. Support for travel to meetings or other purposes from Vivisol. Payment for development of educational presentations from Covidien.

Paolo Navalesi has received fees for consultancy, grants or grants pending, and payment for lectures. Consultancy: Hillrom; Grant: Maquet Critical Care; Payment for lecture: GSK; Royalty: Intersurgical/Starmed.

\section{(c) (1) (-) $\mathrm{ERS}_{2013}$}

HERMES syllabus link module: E.1.6, E.1.12 
effectiveness and clinical benefit is often lacking.

When choosing a HCV, clinicians rely on personal experience and on the results of observational trials $[4,6,8,10,12-24]$. Ideally, the process of choosing a ventilator should be based on a strong scientific rationale founded on predetermined requisites and scores as in the critical care area [25]. Because manufacturers' specifications alone are of limited importance, they should not be a prominent factor in the decision-making process. Basic knowledge of the principles of ventilator functioning [26] may be helpful when choosing a HCV. This enables the physician or respiratory therapist to consider the $\mathrm{HCV}$ technical performance in relation to the patient's clinical characteristics and underlying disease, the home care environment and the available financial resources [27]. The primary purpose of this guide is not to compare the individual features of each ventilator, but rather to provide general information about the technical aspects of such ventilators, which may help in the decision-making process.

\section{Basic principles of ventilator function}

Briefly, a mechanical ventilator can be considered as a series of consecutive functions that turn an input (energy) into a mechanical output (ventilatory variables, such as pressure, flow or volume). The ventilator can transfer energy by applying positive pressure to the airways, acting as a positive pressure ventilator, or by applying sub-atmospheric pressure externally to the chest, as in a negative pressure ventilator. This article will focus solely on positive pressure HCVs. It will not deal with HCVs delivering only continuous positive airway pressure (CPAP) or other ventilators used specifically to treat respiratory sleep disturbances.

There are several elements in a HCV as shown in table 1.

\section{Respiratory circuit}

$\mathrm{HCV}$ s deliver positive pressure to the patient's airway by a system of tubing called the respiratory circuit. The distal part of the respiratory circuit is connected to the patient through an invasive (tracheostomy tube) or noninvasive (mask/mouth-piece) interface.
Table 1 Elements of a positive pressure ventilator

1. Respiratory circuit

2. Pneumatic system

3. Inspiratory and expiratory valves

4. Trigger, limit, cycling and control variables

5. Modes of mechanical ventilation

6. User interface

7. Safety and alarm systems

8. Monitoring system

9. Accessories

There are three main types of circuit, which are sometimes usable interchangeably with each ventilator (e.g. MEK-ICS Pneuma series, Covidien PB $520 / 560$ series, Wienmann Medical Technology Ventilogic series).

\section{Double-limb respiratory circuit}

The double-limb respiratory circuit is composed of an inspiratory and expiratory limb whose proximal ends are connected to the inspiratory and expiratory ports, respectively, of the ventilator (where the inspiratory and expiratory non-rebreathing valve are positioned), while the distal parts are connected to the so-called Y-piece ending in the patient interface (fig. 1). The effective compliance of the respiratory circuit is a combination of the tubing compliance and gas compressibility. Some HCVs provide automatic compensation for circuit compliance and resistances after a calibration manoeuvre (e.g. MEK-ICS Pneuma series, ResMed Elisèe series). Others have the option of choosing between adult and paediatric circuit configurations (e.g. Philips Respironics Trilogy 100/200, Covidien PB $520 / 560$ series). However, some HCVs still lack this automatic compensation Although double-limb respiratory circuits usually measure inspiratory and expiratory tidal volume (VT), they can also be equipped with a proximal flow sensor (fig. 16 ) that can be used either as a simple monitoring tool or to control some of the ventilator functions.

\section{Single-limb circuit}

Single-limb circuits are directly attached to the patient's invasive or noninvasive interface. As use of a single tube for both inspiration and expiration would lead to 
carbon dioxide rebreathing two different systems are used to avoid this problem (fig. 2 and 3).

A single respiratory circuit with a nonrebreathing expiratory valve (e.g. a mushroom valve driven by ventilator pressure) is usually labelled as a "non-vented" respiratory circuit. This valve (fig. 2) has an on-off function and often works as a positive end expiratory pressure (PEEP) valve (see the section on: inspiratory and expiratory valves and output variable control). This type of respiratory circuit allows complete elimination of carbon dioxide. Usually, if they do not have a proximal flow sensor, as shown in figure $1 b$ for the double respiratory circuit, they provide only inspiratory $\mathrm{VT}$ measurement.

A single respiratory circuit without a "true" non-rebreathing valve is usually labelled as a "vented" respiratory circuit or intentional leak respiratory circuit (fig. 3). Carbon dioxide is vented out through different modalities, as shown in figure 3 [28-33] and may be affected by many factors (see part 4 of the recommendations). Inspiratory or expiratory $\mathrm{VT}_{\mathrm{T}}$ are not directly measured but are calculated by an algorithm (see the section dedicated to the monitoring system).

\section{Recommendations}

1) Respiratory circuit features may be different in different ventilators. It may also be possible to use different circuits on the same ventilator according to the patient configuration chosen.

2) Physicians and respiratory therapists must be aware of compressed volume and dead space of respiratory circuits. In paediatric patients, where $V_{T}$ may be very small, respiratory circuit compliance during volume controlled ventilation may affect the real VT delivered to the patient. When automatic compliance compensation is not present, it must be manually calculated as described elsewhere [33].

3) Any connector placed between the Y-piece in a double respiratory circuit, or between the proximal "true non-rebreathing valve" or "vent system" in a single respiratory circuit (fig.s 2 and $3 \mathrm{~b}-\mathrm{c}$ ), and the patient interface (e.g. tracheotomy tube) may affect physiological dead space.

4) When using a ventilator with a "vented" respiratory circuit, PEEP or end expiratory positive airway pressure (EPAP) level, the a)

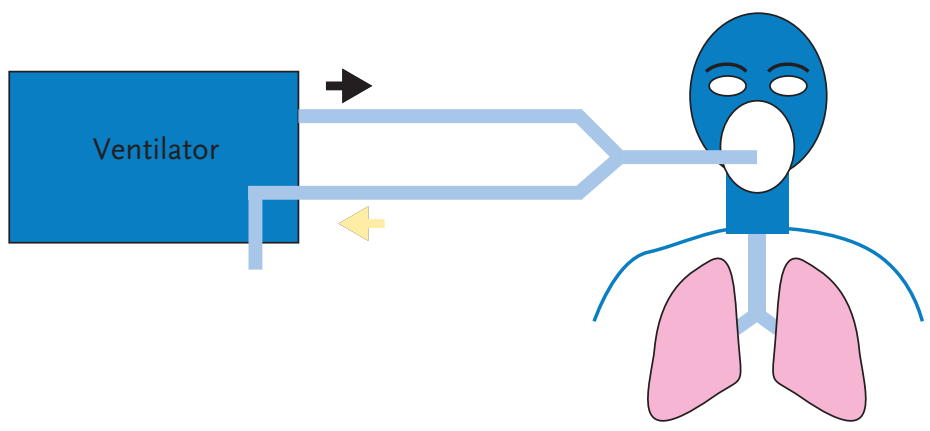

b)

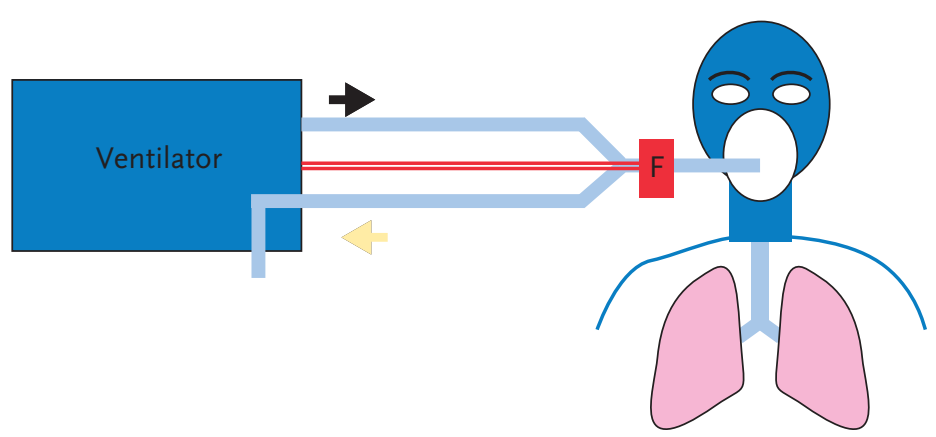

Figure 1

Double limb respiratory circuit a) without and b) with a flow sensor (F) sited distal to the Y-piece. The black and yellow arrows indicate the direction of inspiratory and expiratory flow, respectively. See the main text for further explanation.

a)

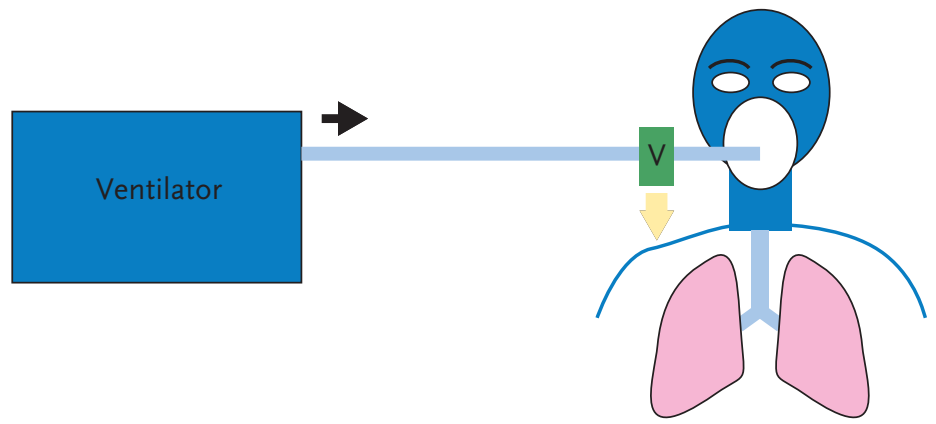

b)

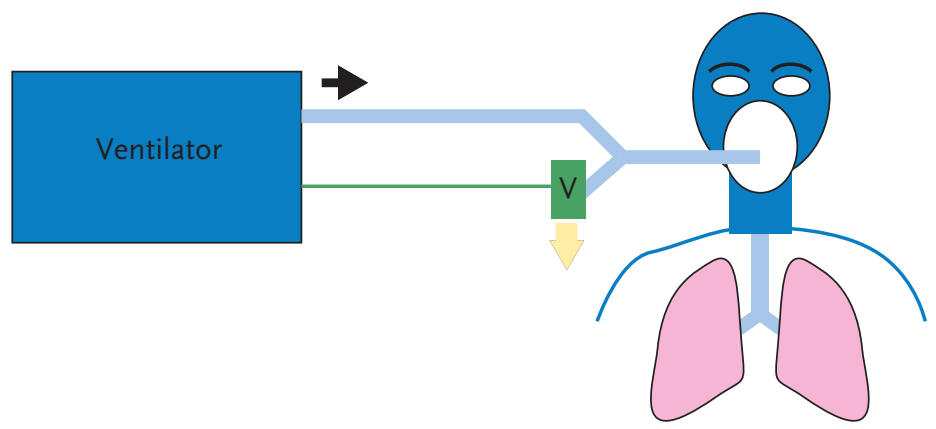

Figure 2

Single limb "non-vented" respiratory circuit with an exhalation valve (V) sited at a) the distal end of the inspiratory circuit or b) at the end of a short expiratory limb. In both cases, the exhalation valve is driven by the ventilator pressure (green line). The black and yellow arrows indicate the direction of inspiratory and expiratory flow, respectively. See the main text for further explanation. 
a)

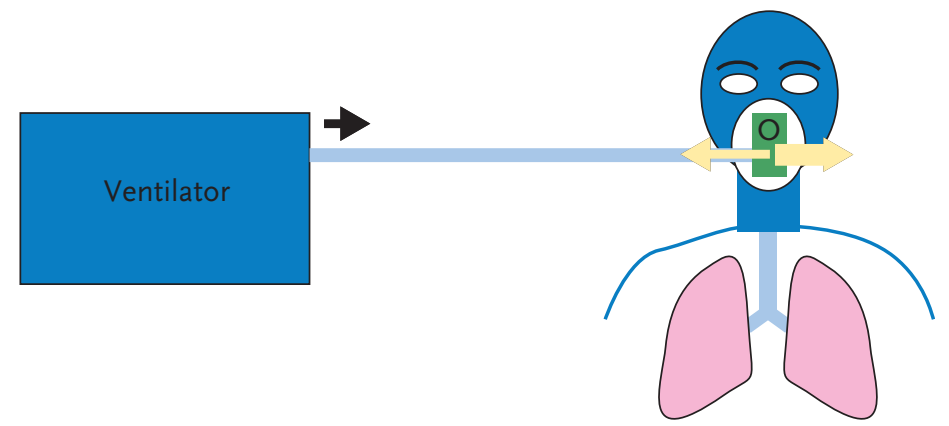

b)

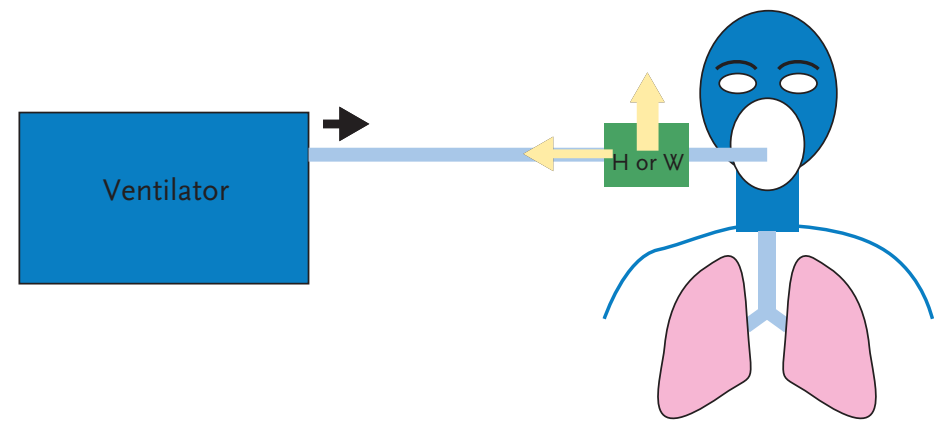

c)

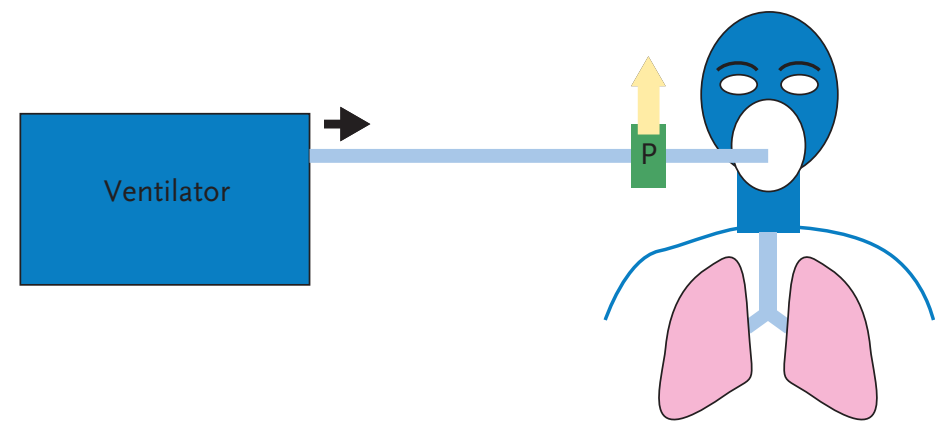

Figure 3

Examples of single limb "vented" circuits. Exhalation occurs through single or multiple orifices sited either in a) the mask shell or in the swivel connector (O), b) a whisper swivel (W) or a hole orifice at the distal end of the circuit $(H)$, or c) a "Plateau Valve" $(P)$ positioned between the circuit and the mask. The black and yellow arrows indicate the direction of inspiratory and expiratory flow, respectively. See the main text for further explanation.
Vivo 50, Covidien PB 520/560, Air Liquide Medical System Monal T series, MEK-ICS Pneuma series, SIARE falco series, ResMed Elisèe series, Versamed/GE i-Vent 150 Hamilton C series, Hoffrichter Carat). Fast turbines ("dynamic blower systems", which change speed to reach the preset ventilator output) or turbines rotating at constant speed ("constant-revolution blower systems") driven by a proportional valve make the latest generation of turbine-driven HCVs as efficient as intensive care unit (ICU) ventilators, driven by high-pressure gas [16]. A recent study showed that, on average, turbine-based ventilators performed better than conventional ventilators [8]. From the standpoint of high responsiveness to the patient's flow demand, "constant-revolution blower systems" with a proportional valve perform very well. However, although in the past these systems had a clear responsiveness advantage over "dynamic blower systems", recent developments show that dynamic blowers with a small blower wheel diameter and a very high revolution rate per minute are also extremely responsive to patient demand $[7,8]$.

\section{Oxygen blending}

Most HCVs only have a low-pressure oxygen inlet. Whatever the inspiratory oxygen fraction $\left(\mathrm{F}_{\mathrm{O}} \mathrm{O}_{2}\right)$ that an internal or external oxygen sensor may read, oxygen delivery is not constant and $\mathrm{FlO}_{2}$ cannot reach $100 \%$. A few HCVs (e.g. Newport Medical Instruments HT7O plus, MEK-ICS Pneuma series, Hamilton $\mathrm{C}_{1}$, GE i-Vent 101 expert) have an option to work with oxygen at high pressure ( $4 \mathrm{~atm}$ or $400 \mathrm{kPa}$ ) and atmospheric air sucked from the environment $[6,23]$. In this case, the preset oxygen tension is constant, whatever the minute volume. The simultaneous use of high-pressure oxygen and a sophisticated user interface make such HCVs suitable as step-down units or for patient transport [23].

\section{Internal battery}

All HCVs have a long-lasting (3-9 h) internal battery, usually with a short charging time [21]. However, battery life may depend on the parameter settings. Some HCVs have a "plug and play" battery system providing energy for up to $12 \mathrm{~h}$ or more. This can be very useful when patients are outside of their usual 
environment or in case of long lasting mains power energy failure. A $12 \mathrm{~V}$ car plug for battery recharging is often available.

\section{Recommendations}

1) Physicians and respiratory therapists must be aware of the differences in terms of gas input and type of control system when choosing HCVs.

2) When a low-pressure oxygen inlet is used, as in the home care setting, oxygen tension is never constant and depends on the parameters set on the ventilator.

3) When choosing HCVs with additional oxygen, oxygen consumption for a given minute ventilation must be taken into account. In some markets, oxygen may be a real cost issue [23].

4) The charge-life of the internal battery, as well as the possibility of using a supplemental battery, must be taken into account for patients who will spend many hours out of their home. This is also important in areas where mains power is frequently interrupted and where electrical back-up is inconsistent.

5) When switching to a mask that has a different intentional leak through the "vent" system, the pneumatic system may fail to deliver the same preset pressure or volume. Careful evaluation is needed to adjust the level of pressurisation $[20,34]$.

\section{Inspiratory and expiratory valves and output variable control}

The inspiratory valve is meant to control respiratory cycle phases, along with the expiratory valve. In most HCVs, the inspiratory valve only has an on-off function: pressure and flow both depend on the mechanical system (e.g. the piston or the rotational speed of the turbine $[26,33])$. In some HCVs, the valve manages the output of the ventilator controlled by a proportional valve [26] (see also the section on: trigger, limit, cycling).

The expiratory valve can be a simple valve that is closed in counter-phase with the inspiratory one (a mushroom or diaphragm valve), or a proportional aperture valve. Usually, expiratory valves also control the baseline pressure, which can be atmospheric pressure or PEEP, also labelled as EPAP. The use of a microprocessor-controlled expiratory valve or an electromagnetic valve can optimise expiratory valve functioning $[6,26,35]$.

As mentioned in above, "vented" respiratory circuits do not have a true nonrebreathing expiratory valve [29-34].

\section{Recommendations}

The "vent system or port" in an intentional leak respiratory circuit is often improperly called a "valve". However, as described above this is not a "true" non-rebreathing valve. Nevertheless, in some ventilator instruction manuals and even in some scientific articles the term "vent system" is improperly replaced with the term "expiratory valve" generating confusion in operators.

\section{Trigger, limit, cycling}

According to the principle of intermittent positive pressure, a positive pressure breath can be defined by: the trigger variable that defines the beginning of inspiration; the limit variable that defines the limit that cannot be exceeded during inspiration; the cycling variable that defines the cycling-off criteria; or the control variable that defines whether the ventilator controls "flow and volume" or "airway pressure" [26, 33].

\section{Trigger variable}

The trigger variable defines how a mechanical breath is initiated. It can be initiated by: 1) pressure (assisted breath pressure-trigger initiated by the patient); 2) flow (assisted breath flow-trigger initiated by the patient); 3) volume (assisted breath volume-trigger initiated by the patient); 4) combining the features described in 1-3; 5) waveform algorithms (assisted breaths algorithms-trigger initiated by the patient); or 6) time (timed mandatory breaths initiated by the ventilator) [26].

The term "assisted" breath usually defines a breath that is initiated by the patient and cycled by the ventilator or is initiated according to some intrinsic property or action of the patient's respiratory system (e.g. flow-cycled breath). In an "assisted" breath the pressure applied to the respiratory system is generated by patient's respiratory muscles and by the ventilator. This makes it different from a "spontaneous" breath (e.g. a CPAP breath in a ventilator delivering in CPAP 
mode), where the inspiratory pressure after patient's triggering does not exceed the baseline pressure (in other words the pressure is negative during the inspiratory phase and positive during the expiratory phase). In addition, in a "spontaneous" breath the pressure applied to the respiratory system is only generated by the patient's respiratory muscles. Cycling to expiration depends on the patient's neural time and the patient's respiratory mechanics. In fact "triggers", as described in steps 1-5, detect any patient inspiratory effort and activate an "assisted" or "spontaneous" mechanical breath. The goal of a good inspiratory trigger is to reduce, as much as possible, the intensity of the muscular effort and the delay between inspiration beginning and the ventilator delivered breath starting, while avoiding autotrigger effects (namely delivery of an inadvertent breath not initiated by the patient's effort). It is considered that a trigger (independent of its algorithm, as described in steps 1-4) must have a response time $<100 \mathrm{~ms}$. While pressure triggering allows detection of a pressure drop within the circuit due to the patient's inspiratory effort, flow triggering is achieved by the measurement of flow variation using a flow sensor inside the ventilator or at the airway opening when a proximal flow sensor is used. Some flow triggers work with the "flow-by system", which provides a continuous bias flow into the circuit with triggering occurring when the difference between the flow entering and exiting through the double-limb respiratory circuit equals the trigger sensitivity [26]. New trigger algorithms also aim to improve patient-ventilator interaction and prevent auto-triggering during sudden changes in flow or respiratory rate, or in the presence of air leaks during noninvasive ventilation (NIV) $[17,36,37]$. This can be achieved with a complex algorithm combining volume and pressure triggers with a flow waveform algorithm (e.g. Philips Respironics AutoTrak).

The term timed "mandatory" breath defines a breath that is always initiated by the ventilator after a given time determined by the respiratory rate set by the operator and cycled by the ventilator. In a "mandatory" breath the pressure applied to the respiratory system is only generated by the ventilator. The inspiratory pressure, as in an "assisted" breath, always exceeds the baseline pressure (zero or a given level of PEEP). Timed breaths can be delivered in any ventilator mode that provides the possibility of setting a respiratory rate (e.g. in the so-called ACV (assisted/ controlled volume mode) or APCV (assisted/ pressure controlled ventilation) in timed ( $T$ ) or spontaneous-timed modes). While in spontaneous-timed, or in assisted/controlled volume or pressure modes the mandatory breaths are only delivered when the patient's spontaneous breathing rate is below the preset one, in timed mode the mandatory breaths are delivered independently from the patient's rate, as during intermittent mandatory ventilation.

\section{Recommendations}

1) When ventilating paediatric patients, a systematic bench evaluation of the inspiratory trigger sensitivity is recommended for every ventilator proposed for home ventilation, in order to detect any dysfunction as well as to guide the choice of the appropriate ventilator for a specific patient $[18,21]$.

2) HCVs provided with a "vented" respiratory circuit and, thus, working with intentional leak algorithms seem to allow better patient-ventilator synchrony [38]. However, high levels of intentional mask leaks through the "vent" port, in intentional leak respiratory circuits may interfere with inspiratory trigger sensitivity [39].

3) Delay in triggering of assisted breaths can be corrected by varying inspiratory trigger sensitivity and the inspiratory rate of pressurisation (pressure rise-time).

\section{Limit variable}

This is the maximal or minimal limit manually set for a mechanical breath (e.g. maximal pressure or maximal inspiratory $\mathrm{VT}$, maximal inspiratory time during flow-cycled breath). It should work as a safety limit variable.

\section{Recommendations}

1) Some ventilators give the possibility of setting a maximum inspiratory time (Tmax) beyond which there will always be a mandatory cycling after a "spontaneous breath" (e.g. pressure support ventilation (PSV), spontaneous and spontaneoustimed modes). 
2) Other HCVs (e.g. Covidien $\mathrm{PB}_{520} / 540$ series, Breas/GE Vivo series) also have, in addition to a Tmax, a minimum inspiratory time ( $T_{\mathrm{min}}$ ) that always assures a minimum inspiratory time in a flow-cycled breath (e.g. spontaneous, spontaneoustimed and timed mode).

\section{Cycling variable}

A breath can be pressure, time, volume or flow-cycled [33]. A breath is defined as timecycled when it is terminated after the given preset inspiratory time is reached (e.g. pressure-controlled time-cycled mandatory breaths). A breath is flow-cycled when the ventilator detects the very end of a patient's inspiration through inspiratory flow measurement and terminates the breath (e.g. spontaneous and spontaneous-timed mode or PSV mode) [40-42]. Table 2 shows the criteria for a flow-cycled breath to cycle to baseline pressure (EPAP or PEEP) $[14,17,26,40]$.

\section{Recommendations}

1) Almost all HCVs enable the operator to set the sensitivity of the threshold of flow termination criteria. It is usually defined as percentage of peak inspiratory flow (e.g. from $2-5 \%$ to $90 \%$ ) or labelled as number (e.g. from 1 to 5). The wider the range, the greater the chance of matching the patient's neural inspiratory time.

2) High levels of non-intentional mask leaks may interfere with the measurement of inspiratory flow threshold prolonging inspiratory time [39].

3) Dys-synchrony in an assisted flow-cycled breath can be corrected by varying the pressure rise-time and/or the threshold of flow cycling criteria, and/or by setting a Tmin and Tmax in spontaneous-timed modes (e.g. ResMed Stellar 100/150 series, Covidien PB 520/560 series, Breas/GE Vivo 40/50 series).

4) It must be also kept in mind that, when using spontaneous-timed mode, the time of a time-cycled breath delivered when the spontaneous patient's rate is below the preset one can be: fixed (e.g. 33\% of the duty cycle (Wienmann Medical technology Ventilogic LS) or adjustable according to a preset inspiratory time (e.g Philips Respironics Trilogy 100/200 series, Breas/ GE Viv050); adjustable according to a preset Tmin (e.g. Covidien PB 520/560 series); or adjustable according to a preset Tmax (e.g. ResMed Stellar).

\section{Control variable}

Mechanical ventilators can apply positive pressure to the airways in different ways, usually divided broadly into volume and pressure ventilatory support. With the former, the independent variable (ventilatory output) is the flow and its integral over time, namely volume. The dependent variable is the pressure, which varies according to the respiratory system impedance. With the latter, the independent variable is the pressure, while flow and volume (dependent variables) are a consequence of the ventilatory impedance and, to a certain extent, the patient's respiratory effort $[26,33]$. When the inspiratory valve has only an on-off function, pressure and flow both depend on the mechanical system (the piston) or on the rotational speed of the turbine ("dynamic blower systems"). In some ventilators working with "constant-revolution blower systems" the control variable may be servo-controlled by an inspiratory proportional valve that manages the output of the ventilator $[25,26]$.

\section{Recommendations}

1) The set-up governing the peak pressure applied to the respiratory system when the independent variable is the "pressure" (pressure targeted modes) may differ between HCVs, as well as within the same unit depending on the setup used. It can be "relative" or "absolute" (e.g. Covidien PB $520 / 540$ series). When using the "relative" set-up with an inspiratory pressure of

Table 2 Criteria for a flow-cycled breath to cycle to baseline pressure

Flow reaches a predetermined percentage of inspiratory peak flow (usually $25 \%$ )

Flow reaches a pre-set percentage of inspiratory peak flow (e.g. from $1 \%$ to $80 \%$ )

According to particular algorithms linked to flow value or waveform (e.g. Philips Respironics AutoTrak system) 


\section{Educational} questions

1) Which of the following is the correct definition of compressed volume of the respiratory circuit?

a) The compressed volume is the volume compressed in the respiratory circuit due to respiratory circuit compliance b) The compressed volume is the volume due the ratio between patient tidal volume and the total volume of the respiratory circuit

c) The compressed volume is the volume compressed in the non-invasive interface

d) All the above mentioned

e) None of the above.

2) Which of the following defines the exhalation port of an intentional leak "vented" respiratory circuit?

a) A system that can be compared to a non-rebreathing valve

b) A system to deliver oxygen c) A system to reduce carbon dioxide rebreathing in intentional leak respiratory circuit d) All the above mentioned e) None of the above
$10 \mathrm{cmH}_{2} \mathrm{O}$ plus PEEP or EPAP $5 \mathrm{cmH}_{2} \mathrm{O}$, the total actual pressure applied to the patient's airway above PEEP or EPAP is $15 \mathrm{cmH}_{2} \mathrm{O}$ (the so-called "above PEEP" setup). In contrast, when applying the "absolute" set-up with the same ventilator setting the total actual pressure applied to the patient's airway is only $10 \mathrm{cmH}_{2} \mathrm{O}$ (the so-called "below PEEP" set-up). This set-up may vary in some units (e.g. Covidien PB $520 / 560$ series) according to the operator choice, generating some confusion. However, most HCVs have a reminder on the main screen of the kind of set-up used and of the peak pressure applied to the airways.

2) A high level of intentional mask leaks through the "vent" port, in intentional leak respiratory circuits may interfere with ventilator pressurisation [39].

\section{Modes of ventilation}

In the past there were ventilators which had only pressure or volume controlled modes. Today most ventilators for life support can work in either mode. HCVs may be provided with a rectangular, descending ramp in volume-targeted mode, or an adjustable pressure rise-time (namely the time needed to reach the preset pressure) and exponential decay in pressure targeted mode [26].

It is beyond the aim of the present article to explain in detail all modes of ventilation. Below we provide some brief information on sighs, mouth piece ventilation and modes of ventilation that switch from one control variable to another (e.g. from pressure to volume-targeted ventilatory support, so-called dual modes) $[26,33,43-50]$.

\section{Sighs}

Despite the lack of a real evidence base about sighs, there is now an increased interest in the sigh option (e.g. Covidien PB 520/560 series, Air Liquide Medical System Monnal T50) and low insufflation programs (e.g. LIAM Wienmann Medical Technological Ventilogic series). Users may define volume or pressure based sighs, their frequency and multiples, as well as their amplitude (+O$50 \%$ of VT or pressure setting). However, in most of the sigh settings, there is no possibility of setting the sigh time. Although there is no evidence in patients ventilated on a long-term basis, recent clinical studies have demonstrated improved oxygenation with the use of sighs as a recruitment manoeuvre in patients with acute respiratory failure [51].

\section{Mouth-piece ventilation}

Some ventilators have a ventilator mode dedicated to mouth-piece ventilation (e.g. Philips Respironics Trilogy 100/200 series, Linde Garbin II, GE i-Vent 101). Its utility has been demonstrated in some patients undergoing NIV $24 \mathrm{~h}$ a day (e.g. in patients with end-stage Duchenne Muscular Dystrophy).

\section{Dual modes}

Although pressure ventilatory support is able to compensate for non-intentional leaks better than volume support [52] a constant VT may not be guaranteed in the presence of changes in respiratory impedance. To overcome this problem, a tidal volume guaranteed (VTG) mode has recently been introduced in most ventilators, during pressure ventilatory support. This mode has been labelled as "dual mode of ventilation" (e.g. Philips Respironics VAPS) [43-48]. The physician or respiratory therapist must be aware that: 1) the VTC can be reached by increasing flow (e.g. ResMed Elisèe) or by increasing the pressure applied to the airway (e.g. Philips Respironics Trilogy, Linde Garmin, Covidien PB 520/560 series, Breas/GE Vivo 50, Wienmann Medical Technology Ventilogic LS); 2) VTC may be adjusted either within each breath (e.g. ResMed Elisèe) or breath by breath (e.g. Philips Respironics Trilogy, Linde Garmin, Covidien PB 520/560 series, Breas/ GE Vivo 50, Wienmann Medical Technology Ventilogic LS) [26, 43]; and 3) VTC may be adjusted either according to the measured inspiratory VT in double or single limb "nonvented" respiratory circuit configuration (Covidien PB 520/560 series, Breas/GEVivo $50)$, the measured expiratory $V T$ in double "non-vented" respiratory circuit configuration (Wienmann Medical Technology Ventilogic LS, Air Liquide Medical system Monnal T50) or according to an estimate of inspiratory or espiratory VT as in "vented" respiratory circuits (e.g. Philips Respironics Trilogy 100/ 200 series, Covidien PB 520/560 series, Breas/GEVivo 50, Res Med Stellar).

A recent study [24] found that the ability of the VTC mode to compensate for 
non-intentional leaks depends strictly on whether a "vented" or "non-vented" circuit configuration is used. Put simply, in the absence of non-intentional leaks in "vented" or "non-vented" respiratory circuit configuration, all HCVs increased the inspiratory pressure to guarantee the VTG. Conversely, in a "non-vented" respiratory circuit configuration, all tested ventilators targeting VTC on the measurement of the inspiratory $V T$ showed a drop in inspiratory pressure in presence of leaks, resulting in a concomitant reduction in expiratory VT. This difference must be taken into account as a possible risk when a VTC mode is used in the presence of non-intentional linear or non-linear leaks [50]. Recently, a new mode of ventilation whose target is not the $V_{T}$ but a given alveolar ventilation (iVAPS ResMed) [46] has become commercially available.

\section{Recommendations}

The physician/respiratory therapist must be aware that: 1) in the presence of modifications of respiratory impedance, VTC mode is able to guarantee a preset volume independently from circuit configuration [49]; 2) there are differences between VTG delivered by "vented" versus "non-vented" single limb respiratory circuits in presence of non-intentional leaks $[24,50]$; 3) when a patient's ventilatory demand produces a $V_{T}$ higher than the preset one, the patient is no longer supported. For this reason, the minimum value of the preset pressure should be carefully set by the operator. Some HCVs allow a minimal default value of PSV (e.g. $5 \mathrm{cmH}_{2} \mathrm{O}$ in Assisted Pressure regulated Volume Control (APRVC) GE i-Vent 101).

\section{User interface}

The control panel allows the user to interact with the ventilator in order to set ventilator parameters and verify them through monitoring the consequent ventilator pattern. Some parameters are set directly, whereas others are derived from measurements. With the current generation of HCVs, the user interface is commonly a touch pad and/or a rotary encoder with or without a touch-screen control. In most HCVs, a two-step process of changing and then accepting a given parameter is used. Most ventilators have the option of locking the ventilator settings to avoid inadvertent manipulation by the ventilator's user. Others leave the care giver with the possibility of modifying some parameters within a given "window" (e.g. Breas/GE Vivo $50)$ set by the physician or respiratory therapist before patient discharge.

However, it has been hypothesised that the user-friendliness of the current home ventilators is questionable. A study that aimed to determine if common home ventilators were user-friendly for trained intensive care unit physicians, without practical experience in home mechanical ventilation, showed that the physicians were slower than the technicians to unlock the ventilator and change the ventilatory mode, with mistakes occurring in close to $50 \%$ of cases during the ventilatory mode and settings recognition test [10].

\section{Recommendations}

1) User interfaces vary significantly among HCVs. Unfortunately there is no consistency among manufacturers in terms of labelling ventilator functions, particularly ventilation modes.

2) The large number of ventilator modes can result in systems that are poorly designed, non-intuitive and almost impossible to remember, with the subsequent need for operators to refer to instruction manuals in order to interpret poorly labelled controls or to navigate multiple levels of software. As a consequence, the physician and respiratory therapist must be aware that there will often be a learning curve for any particular HCV.

3) Last, but not least, another practical consideration is whether the monitor displaying the settings, curves, alarms, etc., is easily readable.

\section{Safety and alarm systems}

\section{Safety system}

The ventilator safety system aims to avoid any damage to the patient due to ventilator malfunction. In case of electrical failure, there is a room-air inlet that will let the patient breathe through a simultaneous opening of the inspiratory and expiratory valves. This may be of little or no help, however, in patients who are not able to breathe spontaneously. Another safety system is the presence of an
3) The likelihood of carbon dioxide rebreathing through the exhalation port of an intentional leak "vented" respiratory circuit may depend on:

a) Amount of PEEP/ EPAP level?

b) Amount of bleeding oxygen in the interface

c) Amount of flow vented through the port

d) Amount of patient's end tidal carbon dioxide e) All the above mentioned

4) In a flow-cycled breath the ventilator detects:

a) The end of patient's own inspiration through inspiratory flow measurement

b) The end of expiratory flow

c) The presence of non-intentional leak d) The presence of the beginning of inspiratory flow e) None of the above

5) The algorithm governing the overall pressure applied to the airway opening is the same for all home care ventilators

( $\mathrm{HCVs}$ )?

a) Yes

b) No, it depends on whether the HCV is driven by a piston or a turbine

c) No, it depends on whether the HCV is in single or doublelimb respiratory circuit configuration 
d) No, it may vary among HCVs and, sometimes, also var ies between modes within the same ventilator

e) None of the above overpressure valve, positioned between the inspiratory and expiratory valves, which can unload any excess pressure in the circuit. In most ventilators, it is usually set to open above a $100 \mathrm{cmH}_{2} \mathrm{O}$ threshold and, thus, it does not limit the risk of barotrauma. Safety systems also include the use of microprocessor-controlled functions, with automated responses for events such as retrograde ventilation in case of apnoea (back-up ventilation).

\section{Alarm system}

The alarm system must alert the care giver of an event that requires their intervention. These events can be technical (i.e. related to ventilator performance) or clinical, due to a change in patient condition. All HCVs should have alarms, as shown in table 3. There are default values for alarm thresholds, beyond which an audible alarm and/or a visual indicator will go off. However, these values should be set case by case according to clinical situation, ventilation mode, type of interface, and possibly modified whenever these conditions change. During NIV it is also advisable to have alarms for significant non-intentional leaks. Non-intentional leaks are characterised by a reduction in airway pressure and expiratory $\mathrm{V}_{\mathrm{T}}$ when in volumetargeted mode, and a rising inspiratory $\mathrm{VT}$ and decreasing expiratory $\mathrm{V}_{\mathrm{T}}$ in pressuretargeted mode when using a "non-vented" double or single respiratory circuit.

\section{Recommendations}

1) All HCVs can be considered life-support devices only if they respond to ventilator malfunctioning with proper alarms (see table 3).

2) It must be remembered that when using a ventilator with an intentional leak circuit ("vented circuit", not provided with a true expiratory valve) there is a risk of rebreathing when the ventilator idles with the patient wearing either an oro-nasal or a total face mask face (covering eyes, nose and mouth) or when using a tracheotomy tube. Although it is not considered a HCV safety system, an anti-suffocation valve embedded in the interface or in the "vented" respiratory circuit is mandatory [53].

3) During NIV, proper alarms on airway pressure and/or expiratory $\mathrm{V}_{\mathrm{T}}$ can be set when needed.

\section{Monitoring system}

The monitoring system is not a part of the ventilator itself and its absence will not jeopardise proper ventilator functioning. However, it is of the utmost importance in optimising ventilatory assistance in most patients. Direct visualisation of flow-time and pressure-time waveforms provides valuable information about the quality of ventilator-patient interaction (e.g. ineffective respiratory efforts, ventilator auto-triggering) [54]. In any ventilator, directly measurable variables are the pressure applied to the airway and the flow, while other parameters can be derived from the analysis of these signals.

Some HCVs display the amount of nonintentional leak in non-vented configuration. In "vented-circuit" configuration, where the amount of leak is always displayed, it is important to know that some ventilators give "figures" that also include the "intentional leaks", while others display a number that refers only to the "non-intentional" leaks (e.g. Covidien PB 520/560 series).

Measured variables and derived parameters may be shown both on a graphical display, and as numerical data. Continuous display of airway pressure, flow and/or volume curves is available with some high performance HCVs. Volume calculation in "non-vented" and in "vented" respiratory circuit configurations may be different.

In "non-vented" respiratory circuits volume is usually calculated through the integration of flow delivered by the ventilator by an internal or proximal flow sensor. However, the accuracy of the volume displayed may vary among different ventilator units $[21,23,55]$. In presence of an intentional inspiratory leak, VT measurements can be confusing because the total flow and the derived volume provided by the ventilator equals the sum of the flow actually sent to the patient plus the leak. This, in turn, means that a higher $\mathrm{V}_{\mathrm{T}}$ is measured. However, if a double respiratory circuit is used, the expiratory $V_{T}$ is more representative of alveolar ventilation than the inspiratory VT. In a double limb respiratory circuit, leak magnitude can be estimated by calculating the difference between the two. This measurement is also featured in ventilators measuring flow proximally to the airways.

In "vented " respiratory circuits, inspiratory $V_{T}$ is not directly measured but is 
calculated through algorithms that vary among HCVs based on the principle that the inspiratory total flow provided by the ventilator equals the sum of the flow actually sent to the patient plus the leak flow from the "vent" system. Some HCVs compute an estimate of the expiratory $\mathrm{VT}_{\mathrm{T}}[56]$. However, it has been shown that the accuracy of $V_{T}$ measurement by the intentional leak ventilator algorithms is not significantly different from that measured by the ventilator flow sensor with a ventilator with a double or single respiratory circuit and the expiratory valve in absence of non-intentional leaks $[24,39,56]$. However, in presence of a high linear or non-linear, intentional or nonintentional, inspiratory or expiratory leak most of this accuracy can be lost $[39,56]$.

Some ventilators allow continuous pulse oximetry monitoring and even end-tidal carbon dioxide monitoring as optional tools. These data and data stored in the ventilator by the ventilator software (tidal volume, leaks and the rate of inspiratory or expiratory triggering by the patient), may help the clinician by estimating ventilation, although further validation of these signals by independent studies is indicated $[39,57]$.

\section{Recommendations}

1) The physician or respiratory therapist should determine which monitoring capabilities will be used regularly in order to avoid purchasing an overly sophisticated $\mathrm{HCV}$ with monitoring systems that will seldom be needed. This should result in cost savings [3]. Basic monitoring should consist of $\mathrm{VT}$, pressures and respiratory rate measurement.

2) It must be borne in mind that the flow sensor accuracy of many ventilators lacks proper validation and, thus, measured data may differ substantially from real values. This issue is very important in paediatric patients [21].

3) In adult patients, there may be no significant differences between the two sites of measurement, distal (inside the ventilator) or proximal (at the airway opening), except for a better detection of the start of inspiration and end of inspiratory effort. By contrast, during ventilation in paediatric patients, where patient flow is lower than in adults and non-intentional leaks are higher due to the

\section{Table 3 Home care ventilator alarms}

1. Electrical failure

2. Patient disconnection from the ventilator

3. High non-intentional leaks

4. Apnoea in assisted modes

5. High and low and minimum patient rate

6. High pressure and low pressure limit (especially in volume-controlled mode)

7. Changes in VT (in pressure-targeted mode)

8. Changes in minute ventilation (in volume- or pressure-controlled modes)

9. Changes in $\mathrm{FIO}_{2}$ when used

use of uncuffed tracheostomy tubes, a proximal transducer may be advised.

4) Clinicians monitoring patients under home ventilation must be aware of differences in the estimation of leaks and $\mathrm{VT}$ by ventilator software and of different ways of reporting leaks according to the device used $[39,55]$.

\section{Accessories}

\section{Heated humidifiers}

Heated humidifiers are often sold separately. It is beyond the scope of the present article to discuss the utility of active or passive humidification in critical care $[53,58]$.

\section{Brackets and carriers}

Brackets are provided in order to mount the $\mathrm{HCV}$ s and an external battery connection, at the patient's bedside or on the wheel chair.

\section{Filters}

HCVs are usually fitted with filters to protect patients and sensors from particulates in the air. Filters are usually disposable.

\section{The patient's point of view}

There is an enormous range of equipment available, but there is little evidence pointing to the superiority of one device over another from the patient's point of view. Another problem is the lack of adaptation of equipment for use by handicapped patients. The point of view of the patients is, thus, clinically relevant, because better patient well-being is related to a better treatment compliance $[9,59,60]$, a critical issue in home ventilation especially in those undergoing NIV. However, data available 


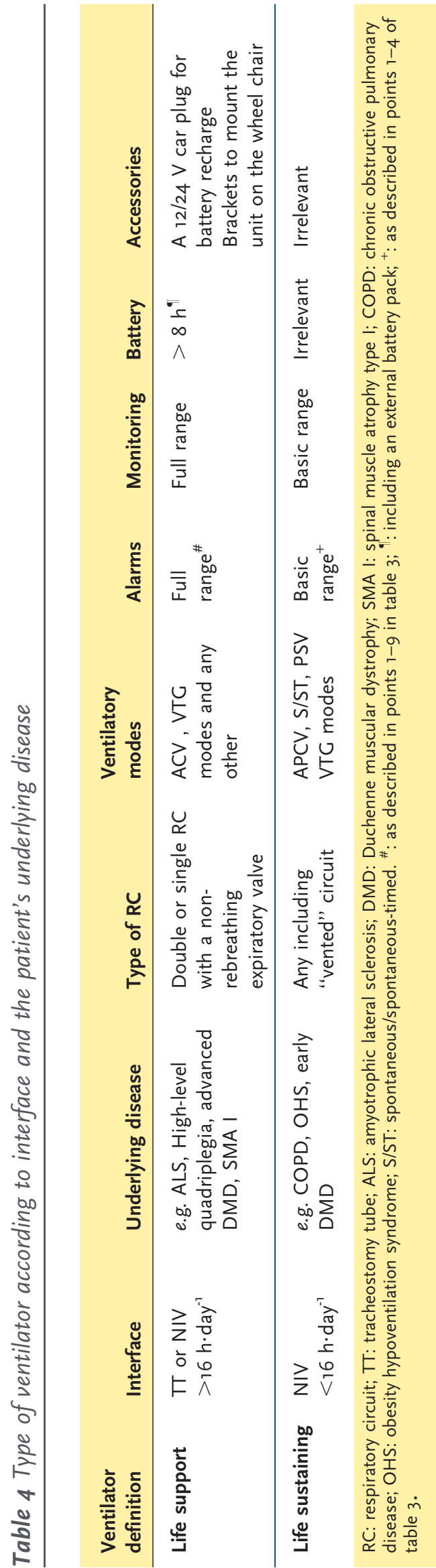

about patient satisfaction regarding mechanical ventilation are very scarce $[5,61]$. There are perceived differences between ventilators, but there is no "perfect ventilator" [9]. Interestingly, one bench study [9] showed that the best ranked of the ventilators also exhibited the fastest pressure rise time. By contrast, some ventilators which were not well tolerated by patients had good bench performances. In spite of the fact that we do not know if the patient's perception has a prognostic impact, good sense suggests that a patient who feels comfortable and relaxed with a particular home ventilator is more likely to comply well with treatment than a patient who does not [9]. Since in many cases the primary objectives of NIV are to alleviate dyspnoea and improve comfort, it does not seem reasonable to exclude the patient's view on the treatment [9].

\section{Recommendations}

1) An assessment of the patient's perception of the ventilator should be part of choosing a ventilator, because small technical characteristics are responsible for differences in patient's perception.

2) In particular, patients selected for NIV should be given the opportunity to express their subjective perception of the ventilator and, if possible, to try several models of ventilator.

3) Patients who report that an established $\mathrm{HCV}$ has become difficult to tolerate for subjective reasons may benefit from trying another ventilator.

4) It is important to test several ventilators, as well as to change them, if the patients' clinical situation changes over time.

\section{Conclusions}

Choosing a HCV should be based on a basic knowledge of machine specific functions and an understanding of the physiological rationale. It is important to understand how these functions interact with the operative environment and patients' needs. Once this goal has been achieved, a ventilator may be chosen based on specific needs (particularly whether safety or comfort is the most important factor), constraints and costs.

There are ventilators that have been designed more for life support than for life sustaining assistance $[23,27]$. From our viewpoint, we consider as "life support" units 
only those highly sophisticated portable ventilators that feature, among other modes, volume controlled ventilation with a nonrebreathing expiratory valve. They must also be equipped with an internal long-life battery, alarms and safety systems to respond to ventilator malfunctioning (e.g. electrical failure) [23], but also allow patient mobility. The physician or respiratory therapist should determine whether the ventilator unit will be used as life support or life sustaining unit. The ventilatory mode chosen will be targeted to a patient's needs in order to avoid purchasing sophisticated but essentially useless ventilatory mode options that will seldom be needed. This should result in cost savings. Some suggestions are given in Table 4 .

Clinical studies and guidelines are required to validate new ventilators and modes of ventilation, to accommodate the increasing demand for treatment while at the same time maintaining high standards both during invasive and noninvasive ventilation $[62,63]$.

\section{References}

1. Windisch W. Quality of life in home mechanical ventilation study group. Impact of home mechanical ventilation health-related quality of life. Eur Respir J 2008; 32: 1328-1336.

2. Cuvelier A, Muir JF. Noninvasive ventilation and obstructive lung diseases. Eur Respir J 2001; 17: 1271-1281.

3. Janssens JP, Derivaz S, Breitenstein E, et al. Changing patterns in long-term noninvasive ventilation: a 7year prospective study in the Geneva Lake area. Chest 2003; 123: 67-79.

4. Lloyd-Owen SJ, Donaldson GC, Ambrosino N, et al. Patterns of home mechanical ventilation use in Europe: results from the Eurovent survey. Eur Respir J 2005; 25: 1025-1031.

5. Vitacca M, Barbano L, D'Anna S, et al. Comparison of five bilevel pressure ventilators in patients with chronic ventilatory failure: a physiologic study. Chest 2002; 122: 2105-2114.

6. Kacmarek RM, Malhotra A. Equipment required for home care ventilation. In: Tobin MJ, ed. Principles and Practice of Mechanical Ventilation. 2nd Edn. New York, McGraw-Hill, 2006; pp. 97-127.

7. Battisti A, Tassaux D, Janssen JP, et al. Performance characteristics of 10 home mechanical ventilators in pressure-support mode: a comparative bench study. Chest 2005; 127: 1784-1792.

8. Thille AW, Lyazidi A, Richard JC, et al. A bench study of intensive-care-unit ventilators: new versus old and turbine-based versus compressed gas-based ventilators. Intensive Care Med 2009; 35: 1368-1376.

9. Senent C, Lepaul-Ercole R, Chiner E, et al. Home mechanical ventilators: the point of view of the patients. J Eval Clin Pract 2010; 16: 832-834.

10. Gonzalez-Bermejo J, Laplanche V, Husseini FE, et al. Evaluation of the user- friendliness of 11 home mechanical ventilators. Eur Respir J 2006; 27: 1236-1243.

11. Branson RD, Johannigman JA. What is the evidence base for the newer ventilation modes? Respir Care 2004; 49: 742-760.

12. Lofaso F, Brochard L, Hang T, et al. Home versus intensive care pressure support devices. Experimental and clinical comparison. Am J Respir Crit Care Med 1996; 153: 1591-1599.

13. Bunburaphong $\mathrm{T}$, Imanaka $\mathrm{H}$, Nishimura $\mathrm{M}$, et al. Performance characteristics of bilevel pressure ventilators: a lung model study. Chest 1997; 111: 1050-1060.
14. Stell IM, Paul G, Lee KC, et al. Noninvasive ventilator triggering in chronic obstructive pulmonary disease. A test lung comparison. Am J Respir Crit Care Med 2001; 164: 2092-2097.

15. Highcock MP, Morrish E, Jamieson S, et al. An overnight comparison of two ventilators used in the treatment of chronic respiratory failure. Eur Respir J 2002; 20: 942-945.

16. Richard JC, Carlucci A, Breton L, et al. Bench testing of pressure support ventilation with three different generations of ventilators. Intensive Care Med 2002; 28: 1049-1057.

17. Miyoshi E, Fujino Y, Uchiyama A, et al. Effects of gas leak on triggering function, humidification, and inspiratory oxygen fraction during noninvasive positive airway pressure ventilation. Chest 2005; 128: 3691-3698.

18. Fauroux B, Leroux K, Desmarais G, et al. Performance of ventilators for noninvasive positivepressure ventilation in children. Eur Respir J 2008; 31 1300-1307.

19. Farré R, Navajas D, Prats E, et al. Performance of mechanical ventilators at the patient's home: a multicentre quality control study. Thorax 2006; 61: 400-404.

20. Borel JC, Sabil A, Janssens JP, et al. Intentional leaks in industrial masks have a significant impact on efficacy of bilevel noninvasive ventilation: a bench test study. Chest 2009; 135: 669-677.

21. Blakeman TC, Rodriquez D Jr, Hanseman D, et al. Bench evaluation of 7 home-care ventilators. Respir Care 2011; 56: 1791-1798.

22. Olivieri C, Costa R, Conti G, et al. Bench studies evaluating devices for non-invasive ventilation: critical analysis and future perspectives. Intensive Care Med 2012; 38: 160-167.

23. Blakeman TC, Branson RD. Evaluation of 4 new generation portable ventilators. Respir Care 2013; 58: 264-272.

24. Carlucci A, Schreiber A, Mattei A, et al. The configuration of bi-level ventilator circuits may affect compensation for non-intentional leaks during volume-targeted ventilation. Intensive Care Med 2013; 39: $59-65$.

25. Chatburn RL, Primiano FP Jr. Decision analysis for large capital purchases: how to buy a ventilator. Respir Care 2001; 46: 1038-1053.

26. Kacmarek RM, Chipman D. Basic principles of ventilator machinery. In: Tobin MJ, ed. Principles and

\section{Suggested answers}

1) a. The physician/ respiratory therapist must be aware of compressed volume in the respiratory circuit. In paediatric patients ventilating in volumetargeted mode, respiratory circuit compliance should be always measured to compute the respiratory circuit compressed volume. 2) c. All intentional leak respiratory circuits ("vented respiratory circuit") must be provided with an exhalation port system to wash out carbon dioxide.

3) e. Many factors can interfere with carbon dioxide rebreathing in a "vented" respiratory circuit. Among them the patient's end tidal carbon dioxide may play a major role.

4) a. In a "flow" cycled breath (e.g. a PSV breath) the ventilator detects the very end of patient inspiration through inspiratory flow measurement.

5) d. The physician/ respiratory therapist must be aware of the algorithm regulating the pressure applied to the airway opening, which can be either "absolute" (below EPAP/PEEP) or "relative" (above EPAP/ PEEP). 
Practice of Mechanical Ventilation. 2nd Edn. New York, McGraw-Hill, 2006; pp. 53-95.

27. Make BJ, Hill NS, Goldberg Al, et al. Mechanical ventilation beyond the intensive care unit. Report of a consensus conference of the American College of Chest Physicians. Chest 1998; 113: Suppl. 5, $289 \mathrm{~S}-344 \mathrm{~S}$.

28. Lofaso F, Brochard L, Touchard D, et al. Evaluation of carbon dioxide rebreathing during pressure support ventilation with airway management system (BiPAP) devices. Chest 1995; 108: 772-778.

29. Ferguson $\mathrm{GT}$, Gilmartin $\mathrm{M} . \mathrm{CO}_{2}$ rebreathing during BiPAP ventilatory assistance. Am J Respir Crit Care Med 1995; 151: 1126-1135.

30. Saatci E, Miller DM, Stell IM, et al. Dynamic dead space in face masks used with noninvasive ventilators: a lung model study. Eur Respir J 2004; 23: 129-135.

31. Schettino GP, Chatmongkolchart $S$, Hess DR, et al. Position of exhalation port and mask design affect $\mathrm{CO}_{2}$ rebreathing during noninvasive positive pressure ventilation. Crit Care Med 2003; 31: 2178-2182.

32. Szkulmowski Z, Belkhouja K, Le QH, et al. Bilevel positive airway pressure ventilation: factors influencing carbon dioxide rebreathing. Intensive Care Med 2010; 36: 688-691.

33. Chatburn RL. Classification of mechanical ventilators. In: Tobin MJ, ed. Principles and Practice of Mechanical Ventilation. 2nd Edn. New York, McGraw-Hill, 2006; pp. 37-52.

34. Louis B, Leroux K, Isabey D, et al. Effect of manufacturer-inserted mask leaks on ventilator performance. Eur Respir J 2010; 35: 627-636.

35. Lofaso F, Aslanian P, Richard JC, et al. Expiratory valves used for home devices: experimental and clinical comparison. Eur Respir J 1998; 11: 1382-1388.

36. Goulet R, Hess D, Kacmarek RM. Pressure vs. flow triggering during pressure support ventilation. Chest 1997; 111: 1649-1653.

37. Tassaux D, Strasser S, Fonseca S, et al. Comparative bench study of triggering, pressurization, and cycling between the home ventilator VPAP II and three ICU ventilators. Intensive Care Med 2002; 28: 1254-1261.

38. Carteaux G, Lyazidi A, Cordoba-Izquierdo A, et al. Patient-ventilator asynchrony during noninvasive ventilation: a bench and clinical study. Chest 2012; 142: $367-376$.

39. Contal $\mathrm{O}$, Vignaux L, Combescure $\mathrm{C}$, et al. Monitoring of noninvasive ventilation by built-in software of home bilevel ventilators: a bench study. Chest 2012; 141: 469-476.

40. Calderini E, Confalonieri M, Puccio PG, et al. Patientventilator asynchrony during noninvasive ventilation: the role of expiratory trigger. Intensive Care Med 1999; 25: 662-667.

41. Tassaux D, Gainnier M, Battisti A, et al. Impact of expiratory trigger setting on delayed cycling and inspiratory muscle workload. Am J Respir Crit Care Med 2005; 172: 1283-1289.

42. Hess DR. Ventilator waveforms and the physiology of pressure support ventilation. Respir Care 2005; 50: 166-186.

43. Amato MB, Barbas CS, Bonassa J, et al. Volumeassured pressure support ventilation (VAPSV). A new approach for reducing muscle workload during acute respiratory failure. Chest 1992; 102: 1225-1234.

44. Storre JH, Seuthe B, Fiechter R, et al. Average volume-assured pressure support in obesity hypoventilation: a randomized crossover trial. Chest 2006; 130: 815-821.

45. Janssens JP, Metzger M, Sforza E. Impact of volume targeting on efficacy of bi-level non-invasive ventila- tion and sleep in obesity-hypoventilation. Respir Med 2009; 103: 165-172.

46. Oscroft NS, Smith IE. A bench test to confirm the core features of volume-assured non-invasive ventilation. Respirology 2010; 15: 361-364.

47. Crescimanno G, Marrone O, Vianello A. Efficacy and comfort of volume-guaranteed pressure support in patients with chronic ventilatory failure of neuromuscular origin. Respirology 2011; 16: 672-679.

48. Murphy PB, Davidson C, Hind MD, et al. Volume targeted versus pressure support non-invasive ventilation in patients with super obesity and chronic respiratory failure: a randomised controlled trial. Thorax 2012; 67: 727-734.

49. Fauroux B, Leroux K, Pépin JL, et al. Are home ventilators able to guarantee a minimal tidal volume? Intensive Care Med 2010; 36: 1008-1014.

50. Bach JR, Alba AS. Tracheostomy ventilation. A study of efficacy with deflated cuffs and cuffless tubes. Chest 1990; 97: 679-683.

51. Pelosi P, Bottino N, Chiumello D, et al. Sigh in supine and prone position during acute respiratory distress syndrome. Am J Respir Crit Care Med 2003; 167: 521-527.

52. Highcock MP, Shneerson JM, Smith IE. Functional differences in bi-level pressure preset ventilators. Eur Respir J 2001; 17: 268-273.

53. Nava S, Navalesi P, Gregoretti C. Interfaces and humidification for noninvasive mechanical ventilation. Respir Care 2009; 54: 71-84.

54. Janssens JP, Borel JC, Pépin JL. Nocturnal monitoring of home non-invasive ventilation: the contribution of simple tools such as pulse oximetry, capnography, built-in ventilator software and autonomic markers of sleep fragmentation. Thorax 2011; 66: 438-445.

55. Lyazidi A, Thille AW, Carteaux G, et al. Bench test evaluation of volume delivered by modern ICU ventilators during volume-controlled ventilation. Intensive Care Med 2010; 36: 2074-2080.

56. Luján M, Sogo A, Pomares X, et al. Effect of leak and breathing pattern on the accuracy of tidal volume estimation by commercial home ventilators: a bench study. Respir Care 2013; 58: 770-777.

57. Pasquina $\mathrm{P}$, Adler $\mathrm{D}$, Farr $\mathrm{P}$, et al. What does built-in software of home ventilators tell us? An observational study of 150 patients on home ventilation. Respiration 2012; 83: 293-239.

58. Navalesi P, Frigerio P, Gregoretti C. Interfaces and humidification in the home setting. Eur Respir Monogr 2008; 41: 338-349.

59. Suzie J, Wood N. Patient satisfaction: a review of issues and concepts. Soc Sci Med 1997; 45: 1829-1843.

6o. Williams B. Patient satisfaction: a valid concept? Soc Sci Med 1994; 38: 509-516.

61. Wielenga JM, De Vos R, de Leeuw RJ, et al. COMFORT scale: a reliable and valid method to measure the amount of stress of ventilated preterm infants. Neonatal Netw 2004; 23: 39-44.

62. Veale D, Gonzalez-Bermejo J, Borel JC, et al. Mise en route d'une ventilation non invasive: pratiques actuelles et evolutions attendues. Enquetes du groupe de travail CasaVNI. [Initiation of long-term non-invasive ventilation at home: current practices and expected issues. Surveys from the CasaVNI working party.] Rev Mal Respir 2010; 27: 1022-1029.

63. Gonzalez-Bermejo J, Perrin C, Janssens JP, et al. Proposal for a systematic analysis of polygraphy or polysomnography for identifying and scoring abnormal events occurring during non-invasive ventilation. Thorax 2012; 67: 546-552. 